\title{
Echoventriculographic detection, localization, and quantification of left ventricular asynergy in acute myocardial infarction A correlative echo- and electrocardiographic study
}

\author{
Juhani Heikkilä and Markku Nieminen \\ From the Cardiovascular Laboratory and the Intensive Care Unit, \\ First Department of Medicine, University Central Hospital, Helsinki, Finland
}

'Echoventriculography', an echocardiographic method specially developed to scan the regional function of the
left ventricle, is introduced for studying left ventricular wall motion alteration in patients with acute
myocardial infarction.
Purposeful probe directions, a $2:$ I magnification, and careful adjustment of the gain and reject levels
allowed a direct echocardiographic scanning of practically the entire left ventricle. Technically acceptable
echoventriculograms were obtained from the upper and lower halves of the septal, anterior, lateral, and postero-
inferior left ventricle segments in all observations on 30 consecutive patients with acute myocardial infarction.
Various degrees of regional left ventricular asynergy were present in roo per cent of the patients with acute
myocardial infarction. In contrast, synergic ventricular segmental wall motion was observed in 40 healthy
subjects. Pronounced asynergy was already detectable within I2 hours from onset of the symptoms of acute
myocardial infarction. Echoventriculography detected acute left ventricular asynergy as well in the antero-
septal or lateral as in the posteroinferior locations. The anterior and/or septal infarction (13 of the 30 patients)
always showed a paradoxical systolic motion of the, generally large, infarcted areas. The amplitude of
abnormal outward motion was up to 5 mm. In the posteroinferior infarctions (I7 patients) akinetic or hypo-
kinetic modes prevailed. The contractile function of the uninvolved segments could be measured at the same
time. Hypercontractile left ventricular wall motion was common in these healthy areas in acute myocardial
infarction. These findings provide useful insight into the various components of the overall left ventricular
pump function in acute myocardial infarction. The validity of the echoventriculographic evaluations of the
segmental left ventricular function subsets was further confirmed in 2 patients undergoing left ventricular
cineangiographic studies and in 2 by necropsy. The site of the asynergic left ventricular wall motion abnormali-
ties correlated excellently with electrocardiographic prediction of the site of acute myocardial infarction. The
echoventriculographic analysis proved to be more accurate in detecting asynergy than was the electrocardio-
gram.

This new echoventriculographic method may become a useful tool for serial noninvasive analysis of left ventricular performance, in detecting both the asynergic areas and the reserve function of the normal regions in acute myocardial infarction.

Regional left ventricular dysfunction develops in every patient with acute transmural myocardial infarction (Tennant and Wiggers, 1935; Heikkilä, Luomanmäki, and Pyörälä, 1971). The size and location of this asynergic contraction are among the major factors that lead to haemodynamic pump Received ro May 1974 . failure and shock (Harrison and Reeves, 1968; Herman and Gorlin, 1969; Zaret, Pitt, and Ross, 1972). Thus, the quantitation of both the dyskinetic infarcted areas and, importantly also, the functional state of the uninvolved myocardium is fundamental for evaluation of these patients.

Biplane cineventriculography would be an accur- 
ate technique for this regional analysis; it is not, however, feasible to use it generally in the acute stages of infarction. The noninvasive methods of cardiac palpation, fluoroscopy, apex- and kinetocardiography, $x$-ray, and electrokymography (Zaret et al., 1972), have remained qualitative only. The new techniques of radarkymography (Kazamias and Gander, 1973) and gated scintiphotography (Zaret et al., 197I) add a more quantitative aspect, but frequently they are not able to record all areas of left ventricular wall motion.

Echocardiography provides a direct, quantitative, and sensitive means for the noninvasive study of cardiac structure and function, including the overall left ventricular pump function (Rackley, Troy, and Pombo, 1973). In human acute myocardial infarction, segmental left ventricular wall motion abnormalities have not as yet been described systematically by echocardiography, though motion of the mainly noninfarcted posterior wall has been described to be 'distorted', as a sign of overall left ventricular dysfunction (Inoue et al., 1971; Wharton, Smithen, and Sowton, I971 ; Ratshin, Rackley, and Russell, 1972). Therefore, a new echocardiographic 'left ventricular scanning' technique was developed to study whether or not (I) the presence of the ischaemic left ventricular dysfunction can be detected in all patients with proven acute myocardial infarction, (2) its anatomical region can be located accurately, and ( 3 ) its size can be quantified in the anterior, septal, inferior, and lateral infarctions as well as in the 'easy' posterior location. The site and extent of the left ventricular asynergic contractions were also correlated with the serial changes of acute infarction in the 12-lead electrocardiograms.

\section{Patients and methods}

Thirty patients who had myocardial infarction, as defined by clear-cut clinical history, serial electrocardiographic abnormalities, and serum enzyme increases (GOT, LDH, CPK) were studied. There were 23 men and 7 women, ranging in age from 30 to 68 years. In 26 patients the infarction was acute and they were admitted to the intensive care unit. The patients were included consecutively, the only criteria of selection being that the infarction was the first one that the patient had experienced. Echocardiography was performed within the first I2 hours from the onset of the symptoms. The scans showing the most abnormal changes during the first week of the infarction (days $1,2,3$, and 7) were selected for the present analysis. Two patients were admitted to the unit because of a deteriorating clinical course about 2 weeks after their acute infarction. Two more patients underwent an angiographic evaluation of recent postinfarction left ventricular aneurysm: one of those was later operated on, the other died because of an intractable low output state. Death of one patient in the acute infarction series was from the same cause.

\section{Electrocardiography}

Twelve-lead serial electrocardiograms were recorded on days $I, 2,3,5$, and 7 of the acute infarction with a 4channel ink-jet Mingograph 34 electrocardiograph (Elema-Schönander, Stockholm). The criteria for localization and extent of the acute myocardial infarction used in this laboratory (Heikkilä, 1967) have been adopted with slight modifications from the principles described by Lipman and Massie (1965). Briefly, the basic localizations of the infarction with their corresponding leads depicting the QRS and/or ST-T changes are the following: anteroseptal (VI-2), anterior (V2-4), anterolateral (V5-6, I, aVL), extensive anterior (VI-6, I, aVL), inferior (II, III, aVF), posterior (VI-2; $R$ waves), infero- and posterolateral (respective combinations).

\section{Echocardiography}

The present 'echoventriculography' was developed specially for evaluation of segmental left ventricular function. It has been developed from the conventional technique described for the study of left ventricular size

\section{POSITION 1; LV DIMENSIONS}

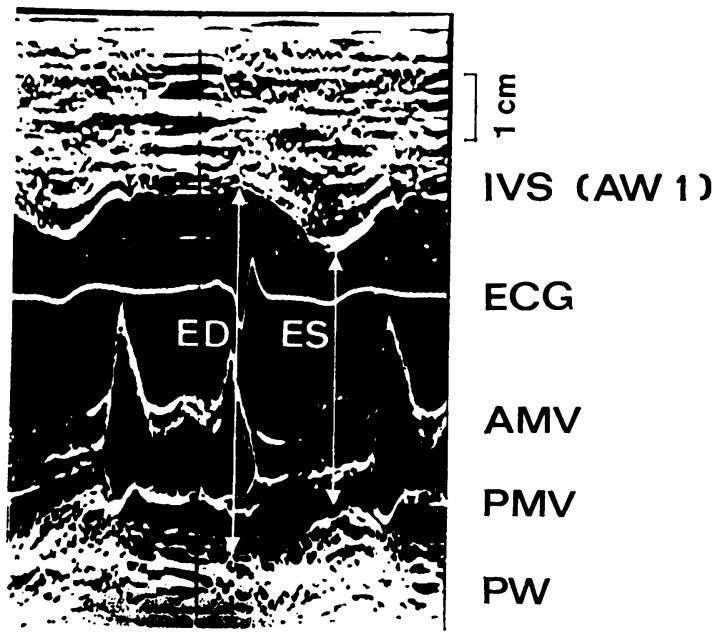

FIG. I The 'landmark' position for left ventricular dimensions, and for subsequent detailed left ventricular segment scanning. Both the anterior $(A M V)$ and posterior (PMV) mitral valve leaflets are shown together with the interventricular septal (IVS) and posterior wall $(P W)$ movements. ED, end-diastolic left ventricular diameter; $E S$, end-systolic left ventricular diameter. 
and function by Feigenbaum (1972). The properties of the Echoview II model A detector (Picker Corp., Cleveland, Ohio) facilitated our approach technically. With this equipment it is possible to use a 2 : I magnification. Errors of measurement are less, and above all, the ventricular wall segments will be visualized much more clearly on this scale. A $2 \mathrm{MHz}$, uncollimated, and unfocused probe was used. The patients were studied in a supine position or with slight elevation of the chest, and during normal respiration.

Probe positions Orientation to the left ventricular cavity begins as usual by first directing the scanning beam to a fixed cardiac 'landmark'. This is defined by obtaining the maximum simultaneous echoes from the posterior and anterior mitral valve leaflets, on the $I: I$ scale, from the $4^{\text {th }}$ intercostal space at the left side of the sternum (Feigenbaum, 1972) (Fig. I). The transverse left ventricular diastolic and systolic diameters are next recorded ( $I: I$ scale) from the same $4^{\text {th }}$ intercostal space but moving the probe medially about I to $2 \mathrm{~cm}$ to the very edge of the left sternal border, sometimes also slightly inferiorly. By slight angulations of the probe, distinctive echoes from both the interventricular septum and the left ventricular posterior wall appear simultaneously (Fig. I). This position of the probe on the thoracic wall is termed basic position $I$.

Scanning position 2 is in the 4 th intercostal space $I \mathrm{~cm}$ lateral to the mitral valve point, that is 2 to $3 \mathrm{~cm}$ lateral to the left sternal border. In the 5 th intercostal space are probe positions 3 and 4 , correspondingly below positions I and 2.

Posterior wall regions Detailed studies of the various left ventricular regions are made in the $2: 1$ magnification. The probe is first directed so that maxi-
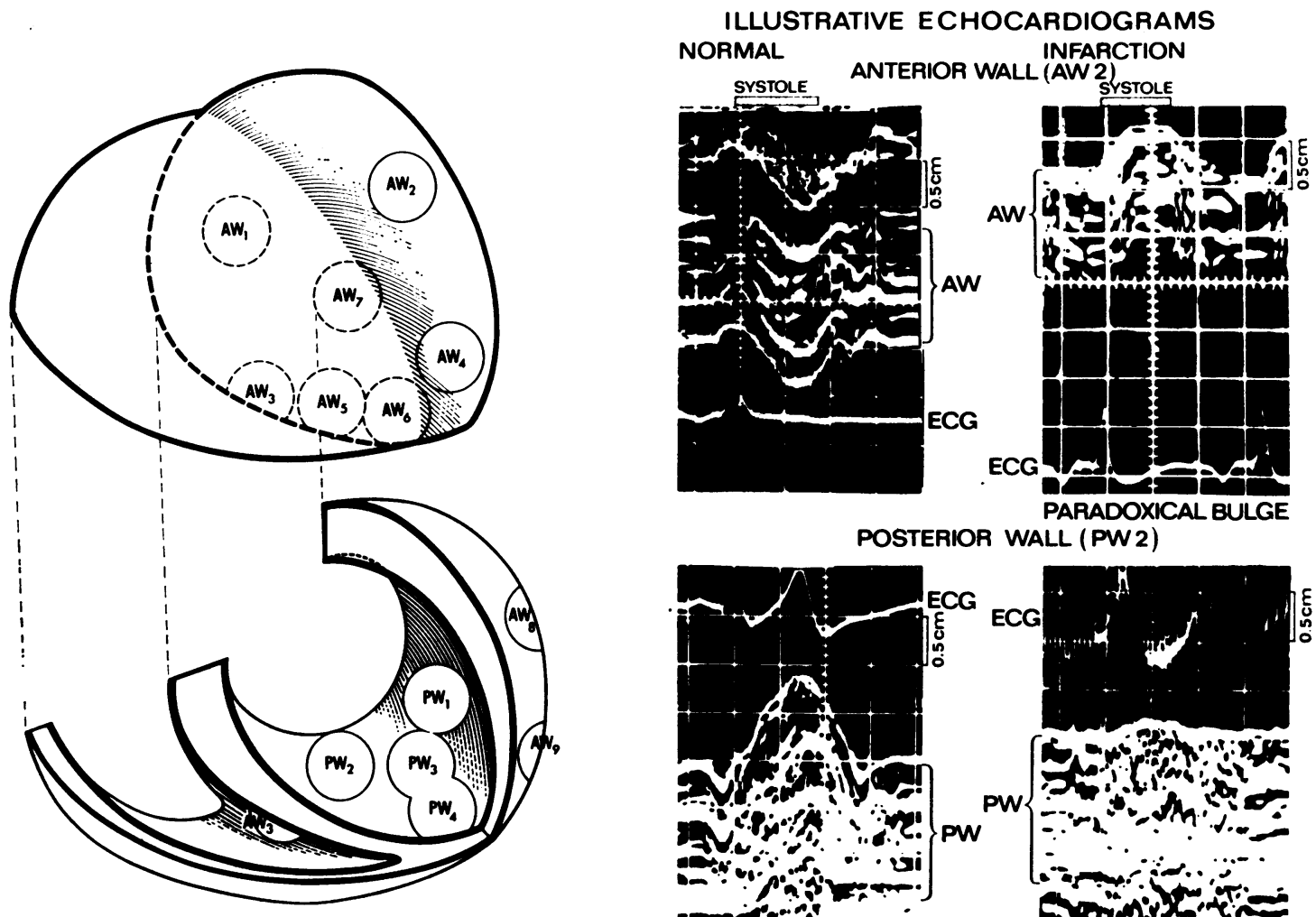

POSTERIOR WALL (PW 2)



FIG. 2 Schematic definition of the basic areas detected by the echoventriculographic left ventricular scanning technique. The four basic directions of the echobeam scan four posterior (PW I to 4) and four anterior wall regions ( $A W I$ to 4). Additional areas from $A W 5$ upwards are rewarding in anterior infarctions. The asynergic changes in the left ventricular wall motion in the actual echograms (right) differ clearly from the normal systolic contraction (left) in both the anterior $(A W)$ and the posterior left ventricular segments $(P W)$. 
mum left ventriclular wall echoes are obtained in that particular position. The gain and reject levels are then adjusted to achieve the best resolution. The maximum time-bound gain was used in the posterior wall scannings. Several M-mode scannings were observed on the storage scope when using varying gain and reject sets. The best of the echobands obtained on each left ventricular region was then photographed with a Polaroid camera installed on the Echoview equipment. The strictly posterior left ventricular wall (PW 2) will be scanned by probe position 2, while lateral areas of the left ventricular posterior wall (PW I) are detected by position $\mathrm{r}$. The inferior half of the left ventricular posterior wall ( $P$ W 3 ) and $P W 4$ ) is recorded from locations 3 and 4 . These anatomical relations are illustrated in Fig. 2.

Anterior wall regions On the anterior side of the heart the above four basic echobeam axes give scannings from the interventricular septum, AW I (high) and AW 3 (low), respectively, and from the left ventricular anterioranterolateral (AW 2) and the anteroapical (AW 4) wall (Fig. 2). Echoes from the septum, again, are initially best conceived on the $I: I$ scale and in the A-mode, while the free left ventricular anterior wall echoes are obtained directly in the 2:I scale. The recognized echoes are marked with the depth beam. This beam was also utilized for the simultaneous electrocardiographic reference recordings. The above 'gating' procedure is necessary because the echoes from the interventricular septum and from the left ventricular free anterior wall are relatively weak. During the subsequent shift to the $2:$ I scale and with the above manipulations they otherwise may become easily lost among the simultaneous double echoes or interference from the right ventricular wall. Maximum near field gain was used for the interventricular septum and anterior wall left ventricular scannings. The best resolution in these regions was usually obtained when the $\mathrm{dB}$ gain and the reject level were about half of the values used for the posterior left ventricular wall.

The probe is directed so that it stands at a right angle against the estimated tangent of each left ventricular anterior wall region under study. To examine the anterior wall infarction comprehensively, several additional left ventricular anterior wall scannings, $A W$ 5, AW 6, AW 7, etc., were recorded. The AW 8 and AW 9 sites especially were very informative in cases of anterolateral infarction (Fig. 2).

The size of the infarcted cardiac region was determined by echocardiography as the number of scanning locations where asynergy of the left ventricular wall contraction became visualized. Asynergy was described as either hypokinesia (locally reduced contraction or asyneresis), akinesia (no motion), or paradoxical movement (systolic bulge or dyskinesia) (Herman and Gorlin, 1969) (Fig. 2).

\section{Comments on the echocardiographic method}

Advantages The present method introduces a standardized echocardiographic scanning system to investigate the regional contraction patterns in the entire left ventricle. Reproducibility is good, as tested in a group of 12 normal subjects (Nieminen, 1974). The 2 : I magnification and careful adjustments of the gain and the reject level modalities allow a greatly improved resolution. This new technique makes it possible to visualize distinctly even the anterior left ventricular wall.

Parallel to the present study, echocardiographic left ventricular scanning has been performed in 40 patients evaluated for coronary artery bypass surgery. The series proved an excellent quantitative correlation between left cineventriculography and echocardiography in the assessment of ventricular asynergy.

As regards orientation with respect to the topography of the left ventricle, the mitral valve point is spatially very strictly defined. Certain physical properties of ultrasound, such as lateral dispersion, make it imperative that in order to obtain echoes simultaneously from both mitral valve leaflets the examining beam must be directed towards them at a right angle. Successful simultaneous visualization of both valve leaflets thus guarantees a correct initial 'landmark' beam direction for subsequent positioning of the above four basic beam



FIG. 3 Above. Low reject level is used in the present method. Though the noise level remains higher the motion pattern is not disturbed, and, importantly, the free anterior wall regions become recordable. Below. With the conventional technique of sharpening endoand epicardial interfaces (arrows) the transmural muscle band is lost. The posterior wall (PW) from the same patient is recorded here with a reject which is 3 times stronger. 
axes to map accurately the segmental left ventricular function, despite the individual variations in anatomical positions of heart within the thoracic cage. With hearts enlarged or displaced from the normal position, it was not difficult to reach the intended anterior, posterior, or lateral wall segments or septum, just by varying the transducer position around the basic scanning points.

Drawbacks Though this technique is capable of scanning in detail most of the left ventricular wall, it is difficult to reach two regions of the left ventricle. These are the basal area of the furthest lateral wall and the posteroseptal corner.

The anterior wall echoes are often only a little stronger than the thoracic wall double echoes and the many dispersional echoes present in the near field. This is why one must be very careful in directing the probe and also in adjusting optimally the gain and reject levels repeatedly during the individual anterior wall scannings (Fig. 3). Not infrequently this becomes a challenge to the investigator's patience. Even after carefully proceeding in the described manner of scanning, some anterior wall echoes may not be seen as a clear boundary in systole but may be represented by a line of dots only. Therefore, it is helpful first to carefully observe the contraction patterns of the left ventricular anterior wall in its dynamic A-mode echoes. This recognizes them and aids in reading them correctly later in the M-mode picture. Despite these sometimes cumbersome technical factors, successful echocardiographic pictures could be recorded from the septal and anterior wall motions in every patient.

The disturbances caused by any rotational and axial movements of the heart are impossible to assess with this technique. However, in the studies with the human heart this has proved to be of minor importance (McDonald, 1970).

\section{Results}

\section{Normal regional contraction pattern}

The systolic contraction of the normal left ventricle is synergic in both the geometric and the sequential sense, as well as when evaluated by 'echoventriculography' (Fig. 2). As a reference, regional left ventricular scanning was obtained by the present method from 40 healthy subjects aged 20 to 40 years. This normal material revealed minor differences in wall excursions and motion sequences between the septal, anterior, posterior, and lateral regions of the normal left ventricle (Fig. 2) (Nieminen, I974). Thus, the septal and anterior wall systolic excursion averaged $5.1 \mathrm{~mm}$ and fractionally preceded the posterior areas, while the systolic posterior wall motion was $8.5 \mathrm{~mm}$. These figures roughly agree with those published by Jacobs et al. (1973).

\section{Detection of ventricular asynergy}

All 30 patients who had sustained acute myocardial infarction demonstrated in the present echocardio- graphic scanning a pathological regional left ventricular contraction. In every case the function of the uninvolved muscle segments could be assessed at the same time. Of the 30 patients, I3 had anterior myocardial infarctions electrocardiographically (anterior, anteroseptal, anterolateral, or their various combinations) and 17 patients had posterior infarctions (posterior, inferior, posterolateral, inferoseptal, or their combinations).

Of the various types of asynergic left ventricular contraction disorders, paradoxical pulsation was noted in a half (in 16 of the 30 patients), akinesia in 8 , and reduction of contraction only (hypokinesia) in 6 patients. The mean excursion of the paradoxical motion was approximately $3 \mathrm{~mm}$ (range I to $5 \mathrm{~mm}$ ) outwards during systole (Fig. 2). Paradoxical pulsation clearly dominated in the anterior infarctions (all of the 13 patients) as compared to the inferoposterior ones (3 of 17), where akinesia (8) or hypokinesia (6) alone occurred.

\section{Localization and extent of left ventricular asynergy}

Both the site and the extent (area and amplitude) of the asynergic region could be quantitatively determined by this echocardiographic left ventricular scanning technique (Tables $I$ and 2). While only one patient showed lesions confined solely to the septum the anterior infarctions frequently extended to the septum, in contrast to the posteroinferior infarctions (Table I). The smallest asynergic area consisted of at least 2 adjacent echocardiographic basic scanning areas (axes I to 4). Most commonly it encompassed 3 adjacent regions, but it could extend to up to 5 of the basic 8 regions (Table 2). The special anterior subscans, from AW 5 and upwards, are not included in these figures because their number varied according to the individual features of the anterior infarction under scanning.

TABLE I Echo localization of asynergic left ventricular segments in acute infarction

\begin{tabular}{lcc}
\hline & $\begin{array}{c}\text { Largest } \\
\text { deviation }\end{array}$ & Extension \\
\hline Anterior & 7 & 6 \\
Anterolateral & 5 & 7 \\
Anteroseptal & $\mathrm{I}$ & 8 \\
$\quad$ Total anterior & 13 & \\
Posterolateral & 13 & 4 \\
Inferior & 3 & 12 \\
Posterior & 1 & 15 \\
Posteroseptal & 0 & 3 \\
$\quad$ Total posterior & I7 & \\
\hline
\end{tabular}


TABLE 2 Relation between echocardiographic and electrocardiographic localizations of acute myocardial infarction

\begin{tabular}{|c|c|c|c|c|}
\hline $\begin{array}{l}\text { Case } \\
\text { No. }\end{array}$ & Asynergic regions detected by echocardiography* & $\begin{array}{l}\text { Electrocardiographic } \\
\text { localization of acute } \\
\text { infarction }\end{array}$ & \multicolumn{2}{|c|}{$\begin{array}{l}\text { Electrocardiograph leads showing } Q \\
\text { waves or heightening of } R \text { waves }\end{array}$} \\
\hline 16 & Anteroseptal, anterior & Anteroseptal & & VI-2 \\
\hline 22 & Anterior, anterolateral & Anterior-anterolateral & I, aVL, & $V_{2}-6$ \\
\hline 17 & Anterior, anterolateral, high septal & Extensive anterior & & VI-5 \\
\hline 25 & Anterior, anterolateral, low septal & Extensive anterior & & VI-5 RBBB \\
\hline 18 & Anterior, anterolateral, high septal, low septal & Extensive anterior & I, aVL, & $V_{2}-6$ \\
\hline $2 \mathbf{I}$ & Anterior, anterolateral, high septal, low septal & Anteroseptal-anterior & I, aVI, & $V_{I}-4$ \\
\hline 13 & Anterior, anterolateral, high septal, low septal & Extensive anterior & aVL, & VI-5 RBBB \\
\hline 34 & $\begin{array}{l}\text { Anterior, anterolateral, high septal, postero- } \\
\text { lateral }\end{array}$ & Anteroseptal-anterior & I, aVL, & $\mathrm{VI}-4$ \\
\hline 8 & Anterolateral, anterior & Anteroseptal-anterior & & $\mathrm{VI}-4$ \\
\hline II & Anterolateral, anterior & Anterior & I, aVL, & $V_{2}-4$ \\
\hline 28 & Anterolateral, anterior, low septal & Extensive anterior & I, aVL, & $V I-5$ \\
\hline 24 & Anterolateral, anterior, high septal & Extensive anterior & I, aVL, & $\mathrm{VI}-6$ \\
\hline 36 & Anterolateral, anterior, inferior & Anterior-anterolateral & I, aVL, & V3-6 LAHB $\left(-80^{\circ}\right)$ \\
\hline Io & Inferior, posterior, posterolateral & Inferior & III, aVF & \\
\hline 9 & Inferior, posterior, posterolateral & Inferior & III, aVF & \\
\hline 23 & Inferior, posterior, posterolateral, high septal & Inferoposterior & III, aVF, & RVI-2 \\
\hline 30 & Posterior, posterolateral, inferior & Inferior & II, III, aVF & \\
\hline 2 & Posterolateral, posterior & Inferoposterolateral & II, III, aVF, & $V_{5}-6, R_{I}-2$ \\
\hline 3 & Posterolateral, posterior $\dagger$ & Inferoposterior & II, III, aVF, & $R V I-2$ \\
\hline 19 & Posterolateral, posterior, inferior & Posterior? & $\left(\mathrm{ST}\right.$ in $\mathrm{V}_{2}-4$ & transiently) \\
\hline 32 & Posterolateral, posterior, inferior & Inferoposterolateral & III, aVF, & V6, RVI-2 \\
\hline 33 & Posterolateral, posterior, inferior & Posteroinferior & III, aVF, & RVI-2 \\
\hline 29 & Posterolateral, posterior, inferior & Lateral & & V6 \\
\hline 6 & Posterolateral, posterior, inferior & Inferoposterior & II, III, aVF, & RVI \\
\hline 5 & Posterolateral, posterior, inferior & Posteroinferior & III, aVF, & $R_{2} 2-3$ \\
\hline 12 & Posterolateral, posterior, inferior & Inferoposterolateral & II, III, aVF, & $V_{5}-6, R_{1-2}$ \\
\hline I4 & Posterolateral, posterior, inferior & Infero(posterior) & II, III, aVF, & $\left(\mathrm{ST} \downarrow \mathrm{VI}_{\mathrm{I}-3}\right)$ \\
\hline 20 & Posterolateral, posterior, inferior, high septal & Inferoposterolateral & II, III, aVF, & $\mathrm{RVI}-2, \mathrm{ST} \uparrow \mathrm{V} 6$ \\
\hline 27 & $\begin{array}{l}\text { Posterolateral, posterior, inferior, high septal, } \\
\text { low septal }\end{array}$ & Inferoposterior & II, III, aVF, & RVI-2 \\
\hline 37 & Posterolateral, inferior, anterolateral & Inferoposteroanterolateral & II, III, aVF, & $\mathrm{V}_{4}-6, \mathrm{RV} 2-3$ \\
\hline
\end{tabular}

* The area of the maximum asynergic motion is stated first.

$\dagger$ Inferior region not scanned.

RBBB, right bundle-branch block; LAHB, left anterior hemiblock.

Interestingly, parallel with the increasing size of the scanned infarction the uninvolved myocardial function tended to become compensatorily 'supernormal'. Increase of its contractile function was expressed by fast and excessive excursions (Fig. 4). This occurred similarly in both anterior and posterior infarctions.

\section{Correlation between electrocardiographic and echocardiographic site and extent of acute infarction}

Complete agreement was obtained in regard to the site of acute myocardial infarction as anterior or posterior when assessed either by echo scannings or by serial 12-lead electrocardiograms (Table 2). This analysis was performed by the two investigators unaware of the result of the other method. No patient had complete left bundle-branch block or multiple infarctions which would have seriously diminished the accuracy of the electrocardiographic estimation.

In contrast, the extent of the infarction diverged when estimated by the two methods. This was clearly related to the site of infarction. In anterior infarctions both echocardiography and electrocardiogram always agreed in displaying a transmural infarction. Anteroseptal involvement, as determined by leads VI-2, also agreed in the two methods, being missed by echocardiography in only I of the Io instances (Table 2). Similarly, the spread of the infarction changes into an increasing number of praecordial $\mathrm{V}$ leads was correlated with an increasing area which showed asynergy in the echocardiographic maps (Table 2, Fig. 4). 
EXTENSIVE ANTERIOR ACUTE MYOCARDIAL INFARCTION IN ECHO

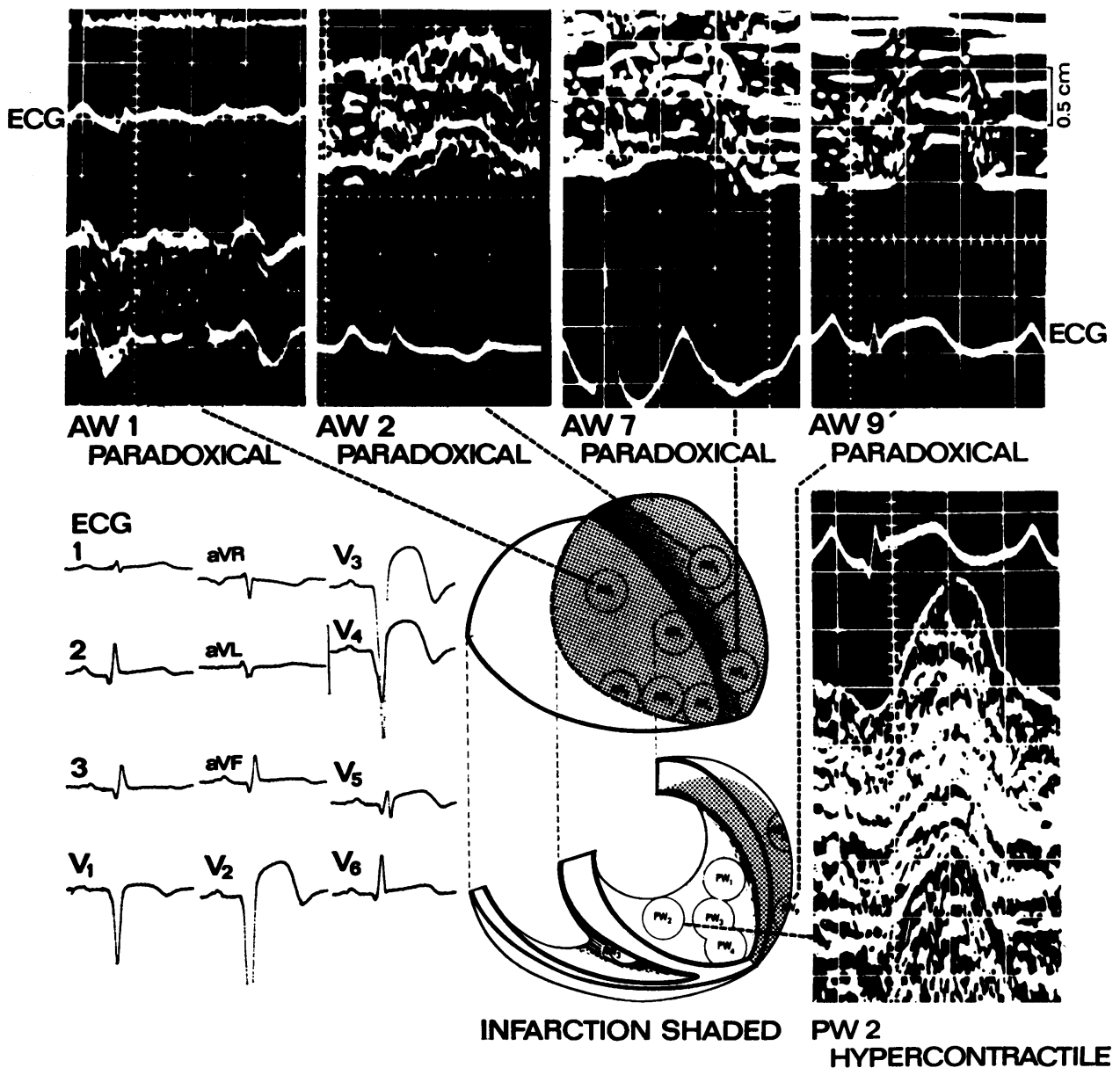

FIG. 4 Echoventriculographic scanning located a pansystolic paradoxical outward motion abnormality over the entire left ventricular anterior wall ( $A W$ I to $A W$ 9) on the and day in a patient with acute infarction. The electrocardiogram correspondingly inscribed $Q$ waves and $S T$ elevations from leads $V_{I}$ to $V_{5}$. A remarkably augmented contractile function, caused by the systolic bulge of the anterior dynamic aneurysm, is recorded in the healthy posterior wall (PW 2).

An illustrative echocardiographic left ventricular scanning from a large inferoposterior infarction is shown in Fig. 5. However, when the infarction was situated in these regions, its actual size was not as easy to estimate even from the QRS alterations in the various electrocardiographic leads. Frequently the echocardiography demonstrated only hypokinetic contraction. Quite often, too, the major echocardiographic localization showed more posterior (lateral) than inferior involvement though the opposite relation was present in the electrocardiogram, i.e. it showed larger inferior and smaller posterior (reciprocal VI-2) changes (Table 2). One patient, despite newly developing large posterior asynergy and higher serum lactic dehydrogenase to 740 IU, showed only a slight and temporary ST depression in the leads V2-3 but no clear QRS alterations (Fig. 6).

In the sequential studies a constant finding was that large akinetic or paradoxically pulsating areas 
INFEROPOSTERIOR ACUTE MYOCARDIAL INFARCTION IN ECHO
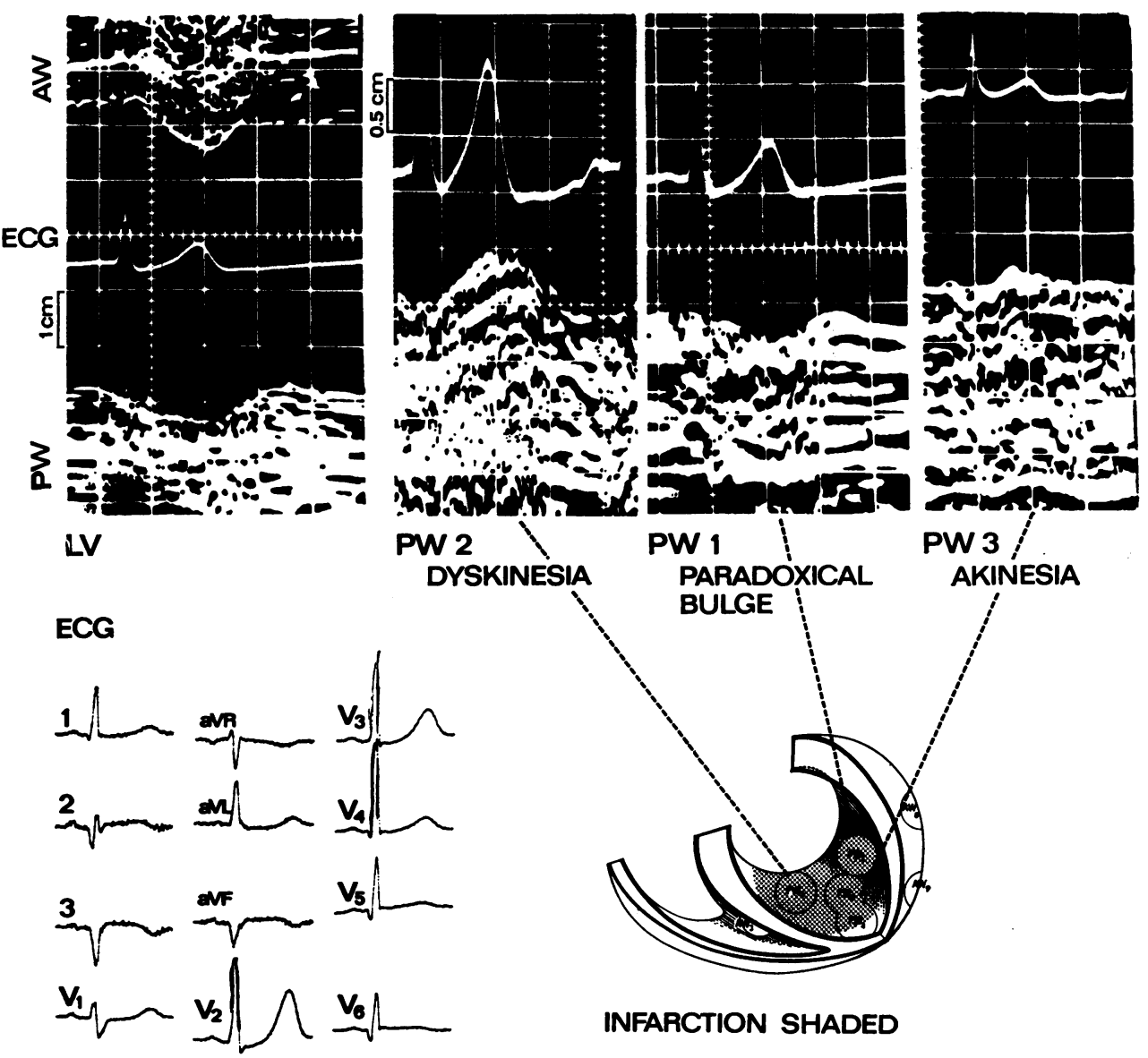

INFARCTION SHADED

FIG. 5 In an inferoposterior acute infarction the echobeam scanned regionally either a slight asynergic contraction in the left ventricular posterior wall (PW 2), pronounced paradoxical motion in the posterolateral wall $(P W I)$, or no motion in the inferior wall $(P W 3)$. The anteroseptal area moves in a normal way $(A W)$.

were detectable already in the very acute stage of infarction ( $<12$ hours), while the electrocardiogram displayed only injury currents (ST elevation) without $Q$ waves (8 patients). This was true irrespective of whether or not $Q$ waves developed later within the next days.

Ventriculographic and anatomical reference of left ventricular asynergy observed by echocardiography

In 2 patients the quantitative ability of the present echocardiographic method in assessing left ventricular function regionally could be correlated with the exact cineventriculographic findings. These studies were performed 6 weeks and 2 months after infarction. The extensive anterior asynergy noted in the cineventriculography was correctly quantified by 'echoventriculography' (Fig. 7). Excessive function of the uninvolved healthy regions was demonstrated similarly by the two methods (Fig. 7). These findings were later supported by cardiac operation in one patient and necropsy in the other.

Two patients died of relentlessly progressive power failure. The location and extent of large anterior infarctions were correctly evaluated by echocardiography before death. In one of these patients an excessive motility of the uninvolved, and 


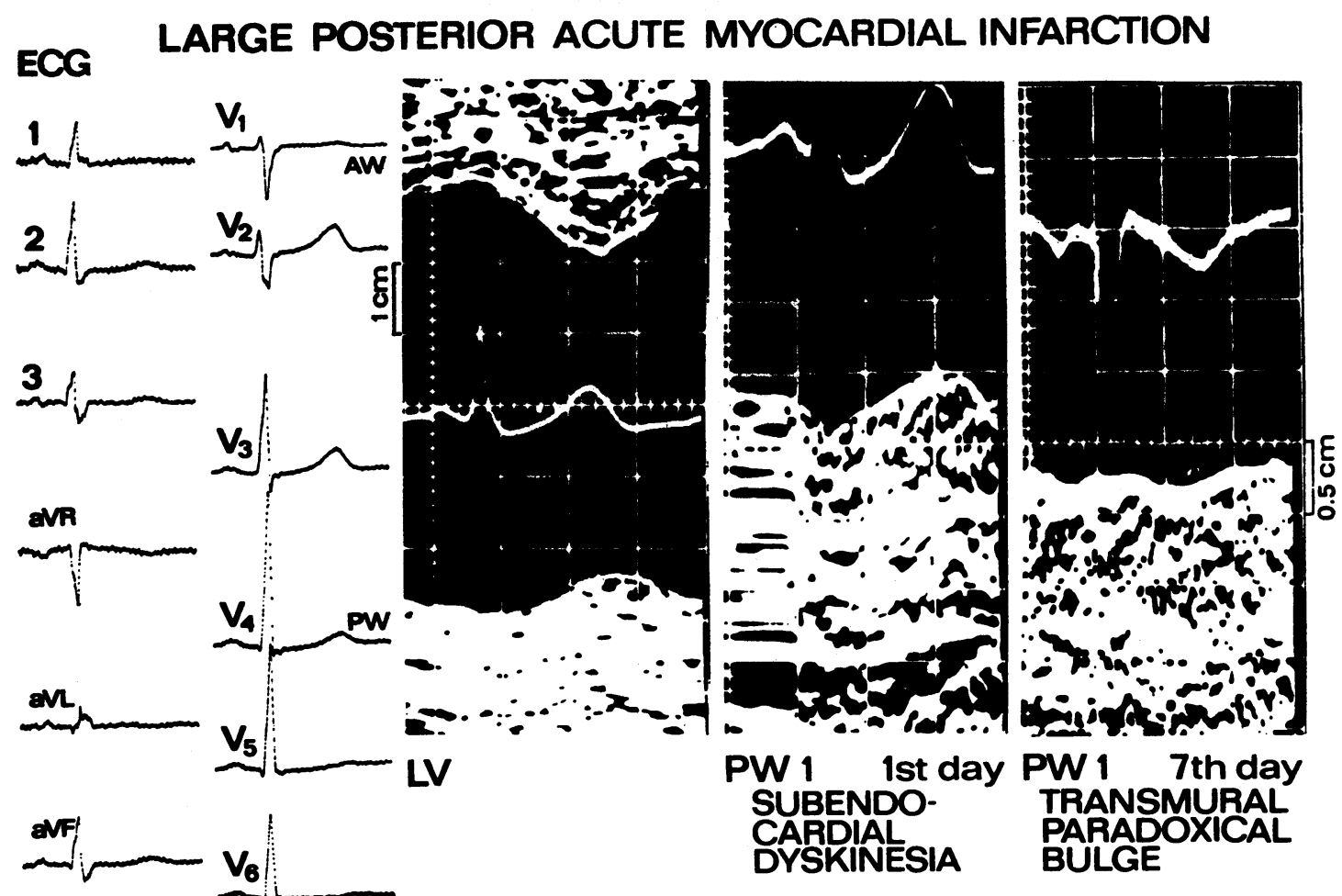

FIG. 6 Strictly posterior myocardial infarction with no conclusive serial electrocardiographic alterations is definitely verified by the progressive loss of segmental ventricular contraction $(P W I)$ in the echocardiographic examinations. The serum lactate dehydrogenase rose to $740 I U$.

microscopically normal, muscle regions was found. Her right coronary artery and left circumflex artery were normal. In the other patient the hypertrophic posterior wall moved sluggishly despite extensive paradoxical pulsation in the anterior wall (Fig. 8). Both of his coronary arteries supplying this noninfarcted region were, however, very hypoplastic and the myocardium showed scattered fibrotic changes in that area. The wall thickness as well as the degree of thinning of the centre areas of the necrosis agreed within I to $2 \mathrm{~mm}$ with the echocardiographic diastolic values (Fig. 8).

\section{Discussion}

Technical features of left ventricular scanning method

The present echocardiographic application developed by us involves new scanning and modulation features which, in contrast to the conventional techniques used so far, expand its capacity remarkably. It provides a means of mapping the regional function of practically the entire left ventricle. The standardized 4 echobeam axes already screen the function at 8 segments around the left ventricle, in the upper and lower halves of the anterior, posterior, septal, and lateral walls, respectively (Fig. 2).

Depending on the site of infarction, the additional scanning directions become very rewarding. These multiple scanning areas all together delineated quantitatively the approximate size and site of the acute left ventricular asynergy in all the infarction patients. A closer search is best made according to the suggestions of the electrocardiographic localization. In fact, an extensive anterolateral infarction was most clearly detected by the AW 8 and AW 9 scans (Fig. 2). Such lateral probe positions do not work in an uninfarcted heart unless there is a dilatatory expansion laterally. Besides the location and area of the infarction, the amplitude of the asynergic systolic motion is very easy to document. The accuracy of echocardiographic scannings is of the order of $1 \mathrm{~mm}$.

In acute myocardial infarction in man, echo- 


\section{POSTINFARCTION ANTERO-APICO-INFERIOR ANEURYSM IN ECHO}
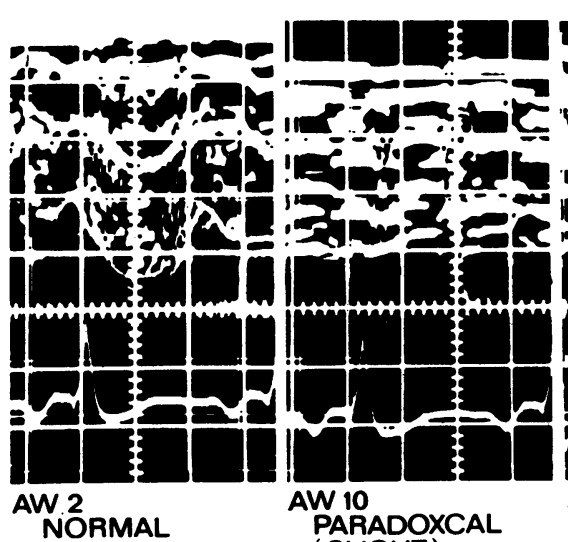

ECG

NORMAL

AW 10

PARADOXCAL

(SLIGHT)

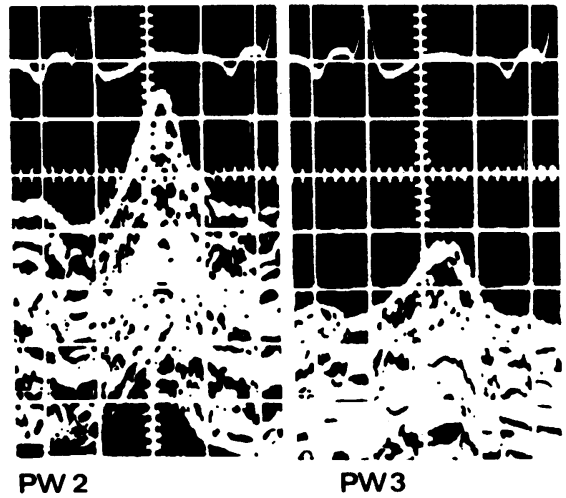

HYPERCONTRACTILE HYPOKINESIA
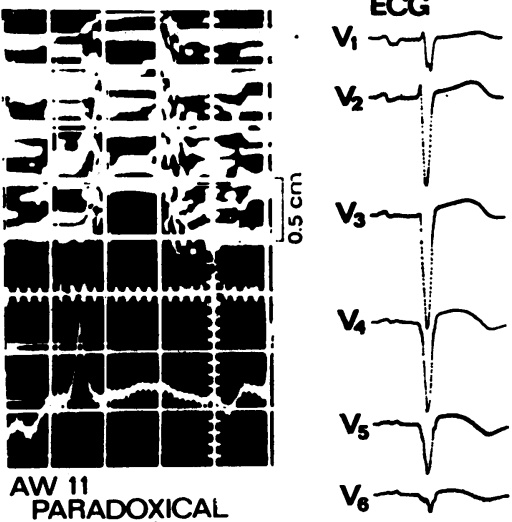

PARADOXICAL (LARGE)
LEFT CINEVENTRICULOGRAPHY



FIG. 7 Echoventriculography located correctly the site and size of a large postinfarction aneurysm, verified by cineventriculography and cardiac operation. Echo measured the internal diameter of the aneurysm as $6.5 \mathrm{~cm}$. The excessive compensatory motion of the healthy basal posterior $\left(P W{ }_{2}\right)$ and high anterior $(A W 2)$ segments was repeated in echo.

cardiography has not been used systematically until now to detect, locate, and measure asynergic regions. Our echocardiographic modification thus offers important augmentation of the ability of ultrasound to explore such basic pathophysiological problems. The 'left ventricular scanning' in fact detected left ventricular asynergy in 100 per cent of the patients with acute phases of myocardial infarction. Previously another study has described the demonstration of ischaemic asynergy located in either the septum or posterior wall in patients with chronic coronary artery heart disease, with a success rate of only 76 per cent, using the conventional left ventricular dimension technique (Jacobs et al., 1973).

It is pointed out herein that the present echo- ventriculographic technique differs fundamentally from that developed earlier for study of left ventricular cavity size and function (Feigenbaum, 1972). After first recording the left ventricular dimensions with the standard method, localization and motion of one ventricular region only at a time are then studied. For these purposes the usual hard purification of the endocardial echoes is irrelevant. On the contrary, the present approach to segmental wall motion avoids the earlier failure of echocardiography in acute myocardial infarction where the success rate of only 60 per cent is usually mentioned.

The consistently correct localization of the normally or abnormally moving left ventricular segments may further depend on a number of other factors. Asynergy in acute transmural myocardia 


\section{FATAL EXTENSIVE ANTERIOR INFARCTION IN ECHO}

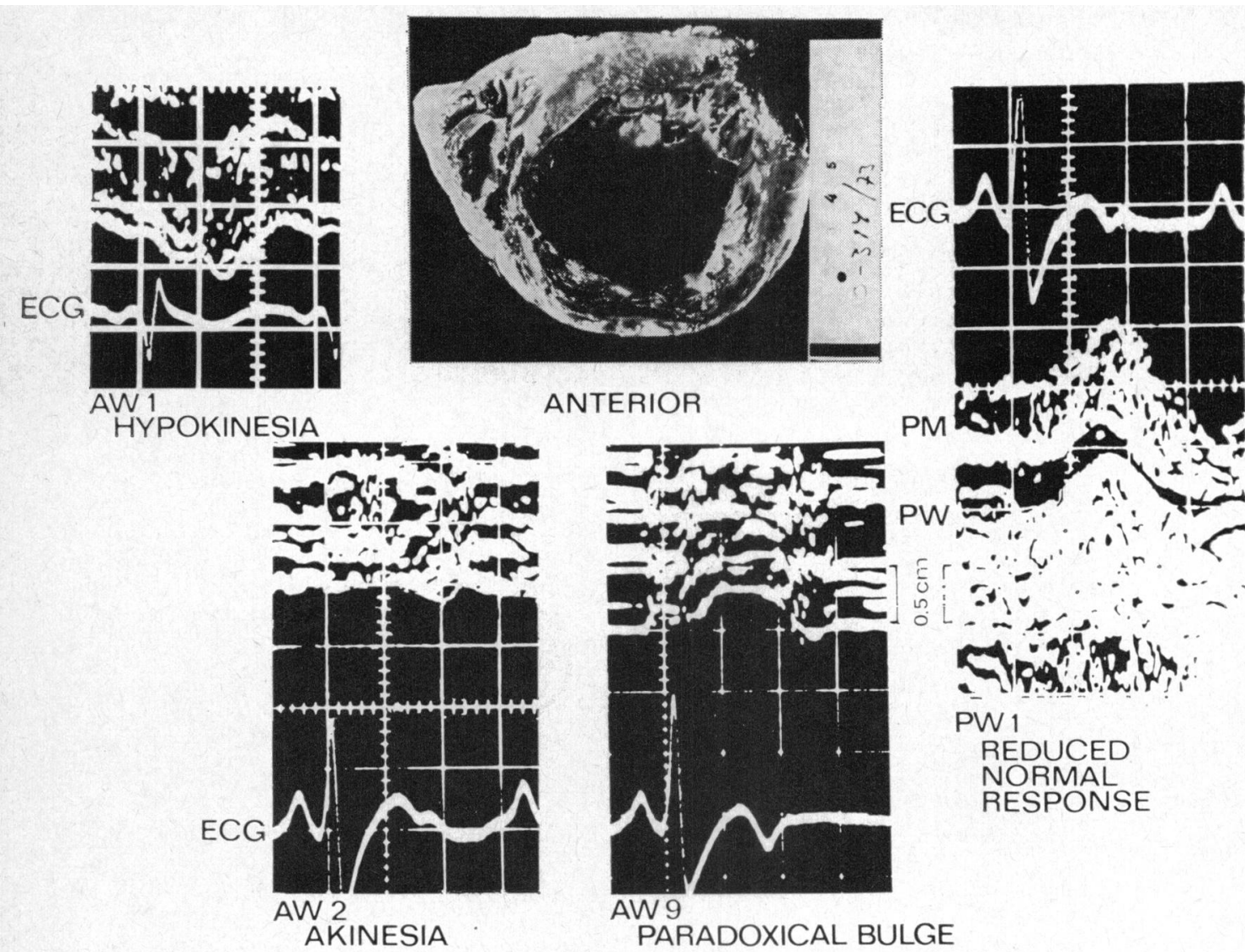

FIG. 8 Varying degrees of left ventricular asynergy, depending on the left ventricular region scanned ( $A W I, A W 2, A W$ 9), in a 34-year-old man with extensive anterior myocardial infarction. Despite the massive acute damage, the posterior wall (PW I; PM=papillary muscle) motion failed the normal compensatory motion in this patient, and this noninfarcted region was in fact supplied by hypoplastic arteries and showed extensive myofibrosis. Death occurred from progressive power failure.

infarction is usually quite severe and encompasses large surfaces. The heart size was not usually greatly increased in these patients with first infarctions. Thus the standard transducer positions on the chest wall, once localized with respect to the mitral valve, would correlate consistently with the ventricle itself. However, our later experience with angiographic and postmortem correlations still confirmed correct echoventriculographic assessment even in very large hearts. The above correlations surpassed those with electrocardiographic localizations which understandably must remain more imprecise.

\section{Pathophysiological aspects}

It has become evident that postinfarction haemodynamic failure and shock are directly related to the size and location of the asynergic segments (Klein, Herman, and Gorlin, 1967; Baxley, Jones, and Dodge, 197I ; Baxley and Reeves, 197I ; Swan et al., 1972; Kitamura et al., 1973). Therefore, detection and quantification of the asynergy give a relevant insight into the significance of an acute infarct. Furthermore, the overall left ventricular function naturally depends heavily on the compensating capacity of the uninvolved segments, and not merely on the size of the asynergic motion. Evalua- 
tion of this function as well as of the nature of the asynergic regions is necessary if corrective cardiac surgery is planned. While noninvasive methods for the above purposes have been qualitative so far, this 'echoventriculography' scanning method provides a quantitative direct means of documenting the subsets of the regional contractions in generating the total left ventricular pump function (Fig. 7 and 8 ). It would also be an excellent screening method before more invasive examinations are applied to the critically ill patients. In our intensive care unit this facility has been very helpful in decision making.

Left ventricular scanning also allows monitoring of the effect of various drug regimens on left ventricular function. For instance, the large 'twilight' ischaemic zone surrounding the actual necrotic centre of infarction may potentially recover, or may progress into a larger infarction (Cox et al., 1968). This frequently depends on haemodynamic factors (Maroko et al., I97I; Watanabe et al., 1972). Thus, echocardiographic scanning may provide a direct noninvasive method to examine the influence of various therapeutic regimens on the contractile function of such vulnerable zones.

\section{Reliability of electrocardiography in localiza- tion and quantitation of acute myocardial infarction}

The electrocardiographic identification of the presence and site of myocardial infarction has frequently been contested as being inaccurate (Simonson et al., 1966; Hilsenrath et al., 1972; Horan and Flowers, 1972). Depending on the site of the infarction the sensitivity varies between 5 and roo per cent (Sodi-Pallares et al., 1963). In those studies, however, cross-sectional electrocardiographic tracings and the rather insensitive and hard criteria established for epidemiological purposes have usually been applied (Simonson et al., I966).' However, it is during the acute stage that the localization of the first one or two transmural infarctions seems to be quite accurately determinable. At that time the characteristic QRS and ST-T changes available from serial tracings greatly improve the ability to pin point the site of the infarct.

Thus, the results of the present double-blind study revealed that the site of the acute asynergic left ventricular wall motion abnormalities correlated excellently with the electrocardiographic prediction of the site of the acute infarction damage. In an earlier necropsy comparison from this laboratory, all acute transmural infarctions were similarly correctly localized by acute stage serial electrocardiograms (Heikkilä, 1967). These good correlations observed in our series are further supported strongly by the very recent findings by three groups (Miller et al., 1972; Jacobs et al., 1973; Williams et al., 1973) in living patients with chronic coronary artery heart disease. An intimate relation existed between the angiographic site of left ventricular asynergy, coronary artery obstruction, and electrocardiographic localization of the myocardial infarction.

Anterior myocardial infarction clearly showed a better quantitative electrocardiographic correlation to the anatomical extent of the asynergic motion than was the case in inferoposterior infarctions. The proximity of the praecordial V-leads to septal and free anterior wall infarctions would explain this sensitivity. But it is noteworthy that extensive paradoxically pulsating segments were present in the very early hours of infarction, at the time when $Q$ waves had not yet developed. This again gives good evidence of how the ischaemia alone, before development of infarction or necrosis, suddenly abolishes the mechanical function of large segments of the left ventricle (Tennant and Wiggers, 1935; Amsterdam, 1973).

In contrast, posterior infarction is detected only by the praecordial mirror-image changes in the standard 12-lead electrocardiogram, inferior wall involvement by the few frontal plane leads II, III, and aVF, and high lateral lesions just by the remote aVL lead. Thus their quantitative estimations by electrocardiogram must remain very limited because of the above electrophysiological relation. Failing to identify even a large transmural acute infarction by electrocardiogram is possible in these regions (Fig. 6; Case 19, Table 2). Interestingly, our result where the echocardiographic asynergy prevailed in the posterolateral regions in the presence of dominating inferior electrocardiogram localization is completely in agreement with the similar relation noted by Horan and Flowers (1972) in their electrocardiographic anatomical studies. The superiority of the echocardiographic left ventricular scanning technique in directly assessing the extent of asynergic motion is obvious on the basis of our echoelectrocardiogram correlative results. Subendocardial infarction is very difficult to localize by the ST-T changes (Cook, Edwards, and Pruitt, I958; Abbott and Scheinman, 1973). Echocardiography may detect even these small infarctions directly by regional wall motion abnormalities.

Differences between anterior and posterior left ventricular wall asynergy in echocardiography

In general, echocardiography demonstrated a wide spectrum of left ventricular motion abnormalities. It ranged from only small-sized lesions and only 
slight local hypokinesia to massive infarctions and pansystolic paradoxical bulges encompassing large segments of the left ventricle. The present echocardiographic study confirms the earlier finding that an anterior infarction usually involves large regions of the left ventricle, with more serious haemodynamic consequences and prognosis than is the case with inferoposterior infarctions (James, I968; Ratshin, Massing, and James, I973; Russell, Hunt, and Rackley, 1973). The anterior infarctions were always large in echocardiography (mean about 5 positions), and consistently showed more or less paradoxical outward motion. This systolic bulge increased in parallel with the enlarging area of the asynergic motion. By contrast, the posteroinferior infarctions frequently were akinetic or even hypokinetic only, the paradoxical pulsation being an exception. They usually encircled a smaller segment (mean about 3 positions).

The lesser degree of paradoxical motion in the posterior infarctions may be related to their smaller size caused by the double vascular supply of these regions (James, I968; Russell et al., 1973). However, this more akinetic pattern was seen also in quite extensive posteroinferior infarctions which resulted in a serious clinical condition and remarkable enzyme rises. A true paradoxical motion may, in these cases, be nullified in the echocardiogram into a mere akinetic tracing if the heart as a whole simultaneously shifts anteriorly during systole. It is a moot point if any such mass motions take place in infarction, though some recent evidence supports this possibility (Sniderman, Marpole, and Fallen, 1973). This possible shift would also then inadvertently result in a 'too good' echocardiographic finding of the left ventricular motion disorder. Furthermore, Sniderman et al. (1973) and Vogel, Cornish, and McFadden (1973) have shown that the posterolateral and inferior left ventricular segments clearly contribute more to the normal overall left ventricular motion than do the septal and anterior segments (the same was observed in our normal material). Whether this slight inequality is somehow reflected as less asynergy of these segments, when eventually becoming infarcted, remains to be investigated. The paradoxical motion began early in the isovolumic phase of the systole, confirming our earlier findings in experimental myocardial infarction in cineradiological marker studies (Heikkilä, Tabakin, and Hugenholtz, 1972).

\section{References}

Abbott, J. A., and Scheinman, M. M. (1973). Nondiagnostic electrocardiogram in patients with acute myocardial infarction. Clinical and anatomic correlations. American fournal of Medicine, 55, 608.
Amsterdam, E. A. (1973). Function of the hypoxic myocardium. Experimental and clinical aspects. American fournal of Cardiology, 32, 461.

Baxley, W. A., Jones, W. B., and Dodge, H. T. (I97I). Left ventricular anatomical and functional abnormalities in chronic postinfarction heart failure. Annals of Internal Medicine, 74, 499.

Baxley, W. A., and Reeves, T. J. (1971). Abnormal regional myocardial performance in coronary artery disease. Progress in Cardiovascular Diseases, 13, 405.

Cook, R. W., Edwards, J. E., and Pruitt, R. D. (1958). Electrocardiographic changes in acute subendocardial infarction. I-II. Circulation, 18, 603 and 613.

Cox, J. L., McLaughlin, V. W., Flowers, N. C., and Horan, L. G. (1968). The ischemic zone surrounding acute myocardial infarction. Its morphology as detected by dehydrogenase staining. American Heart fournal, 76, 650.

Feigenbaum, H. (1972). Echocardiography. Lea and Febiger, Philadelphia.

Harrison, T. R., and Reeves, T. J. (1968). Myocardial ischemia and cardiac dyssyngergy. In Principles and Problems of Ischemic Heart Disease, p. I17. Year Book Medical Publishers, Chicago.

Heikkilä, J. (1967). Mitral incompetence as a complication of acute myocardial infarction. Acta Medica Scandinavica, 182, Suppl. 475.

Heikkilä, J., Luomanmäki, K., and Pyörälä, K. (197I). Serial observations on left ventricular dysfunction in acute myocardial infarction. I. Gallop sounds, ventricular asynergy and radiological signs. Acta Medica Scandinavica, 190, 89.

Heikkilä, J., Tabakin, B. S., and Hugenholtz, P. G. (1972). Quantification of function in normal and infarcted regions of the left ventricle. Cardiovascular Research, 6, 516.

Herman, M. V., and Gorlin, R. (1969). Implication of left ventricular asynergy. American fournal of Cardiology, 23, 538.

Hilsenrath, J., Hamby, R. I., Glassman, E., and Hoffman, I. (1972). Pitfalls in prediction of coronary arterial obstruction from patterns of anterior infarction on electrocardiogram and vectorcardiogram. American fournal of Cardiology, 29, 164 .

Horan, L. G., and Flowers, N. C. (1972). Diagnostic power of the $Q$ wave: critical assay of its significance in both detection and localization of myocardial deficit. In Advances in Electrocardiography, p. 321 . Ed. by R. C. Schlant and J. W. Hurst. Grune and Stratton, New York.

Inoue, K., Smulyan, H., Mookherjee, S., and Eich, R. H. (I97I). Ultrasonic measurement of left ventricular wall motion in acute myocardial infarction. Circulation, 43, 778.

Jacobs, J. J., Feigenbaum, H., Corya, B. C., and Phillips, J. F. (1973). Detection of left ventricular asynergy by echocardiography. Circulation, 48, 263.

James, T. N. (1968). The coronary circulation and conduction system in acute myocardial infarction. Progress in Cardiovascular Diseases, 10, 410.

Kazamias, T. M., and Gander, M. P. (1973). Left ventricular wall motion disorders, functional left ventricular aneurysms. Their detection by radarkymography. American fournal of Cardiology, 32, 151.

Kitamura, S., Kay, J. H., Krohn, B. G., Magidson, O., and Dunne, E. F. (I973). Geometric and functional abnormalities of the left ventricle with a chronic localized noncontractile area. American fournal of Cardiology, 31, 701.

Klein, M. D., Herman, M. V., and Gorlin, R. (1967). A hemodynamic study of left ventricular aneurysm. Circulation, 35, 614.

Lipman, B. S., and Massie, E. (1965). Clinical Scalar Electrc- 
cardiography, 5th ed. Year Book Medical Publishers, Chicago.

McDonald, I. G. (1970). The shape and movements of the human left ventricle during systole. Study by cineangiography and by cineradiography of epicardial markers. American fournal of Cardiology, 26, 221.

Maroko, P. R., Kjekshus, J. K., Sobel, B. E., Watanabe, T., Covell, J. W., Ross, J., Jr., and Braunwald, E. (1971). Factors influencing infarct size following experimental coronary artery occlusions. Circulation, 43, 67.

Miller, R. R., Mason, D. T., Massumi, R. A., Zelis, R., and Amsterdam, E. A. (1972). ECG determination of nature, location and extent of abnormal ventricular segmental contraction in coronary artery disease. Circulation, 46, Suppl. 2, 9.

Nieminen, M. (1974). The normal echoventriculography. Annals of Clinical Research. In the press.

Rackley, C. E., Troy, B., and Pombo, J. F. (1973). Left ventricular dimension and mass determined by echocardiography. In Myocardial Infarction, p. 135. Ed. by E. Corday and H. J. C. Swan. Williams and Wilkins, Baltimore.

Ratshin, R. A., Massing, G. R., and James, T. N. (1973). The clinical significance of the location of acute myocardial infarction. In Myocardial Infarction, p. 77. Ed. by E. Corday and H. J. C. Swan. Williams and Wilkins, Baltimore.

Ratshin, R. A., Rackley, C. E., and Russell, R. O., Jr. (1972). Serial evaluation of left ventricular volumes and posterior wall movement in the acute phase of myocardial infarction using diagnostic ultrasound (abstract). American fournal of Cardiology, 29, 286.

Russell, R. O., Jr., Hunt, D., and Rackley, C. E. (1973). Left ventricular hemodynamics in anterior and inferior myocardial infarction. American fournal of Cardiology, 32, 8.

Simonson, E., Tuna, N., Okamoto, N., and Toshima, H. (1966). Diagnostic accuracy of the vectorcardiogram and electrocardiogram. A cooperative study. American fournal of Cardiology, 17, 829.

Sniderman, A. D., Marpole, D., and Fallen, E. L. (1973). Regional contraction patterns in the normal and ischemic left ventricle in man. American fournal of Cardiology, 31, 484 .
Sodi-Pallares, D., Bisteni, A., Cisneros, F., DeMicheli, A., Medrano, G. A., and Testelli, M. R. (1963). Reliability of the electrocardiogram in diagnosis of myocardial infarction. In Coronary Heart Disease, p. 278. Ed. by W. Likoff and J. H. Moyer. Grune and Stratton, New York.

Swan, H. J. C., Forrester, J. S., Diamond, G., Chatterjee, K., and Parmley, W. W. (1972). Hemodynamic spectrum of myocardial infarction and cardiogenic shock. A conceptual model. Circulation, 45, 1097.

Tennant, R., and Wiggers, C. J. (1935). Effect of coronary occlusion on myocardial contraction. American fournal of Physiology, 112, 351.

Vogel, J. H. K., Cornish, D., and McFadden, R. B. (1973). Underestimation of ejection fraction with singleplane angiography in coronary artery disease: role of biplane angiography. Chest, 64, 217.

Watanabe, T., Covell, J. W., Maroko, P. R., Braunwald, E., and Ross, J., Jr. (1972). Effects of increased arterial pressure and positive inotropic agents on the severity of myocardial ischemia in the acutely depressed heart. American fournal of Cardiology, 30, $37 \mathrm{I}$.

Wharton, C. F. P., Smithen, C. S., and Sowton, E. (1971). Changes in left ventricular wall movement following acute myocardial infarction measured by reflected ultrasound. British Medical fournal, 4, 75.

Williams, R. A., Cohn, P. F., Vokonas, P. S., Young, E., Herman, M. V., and Gorlin, R. (1973). Electrocardiographic, arteriographic and ventriculographic correlations in transmural myocardial infarction. American fournal of Cardiology, 31, 595.

Zaret, B. L., Pitt, B., and Ross, R. S. (1972). Determination of the site, extent, and significance of regional ventricular dysfunction during acute myocardial infarction. Circulation, 45, 44I.

Zaret, B. L., Strauss, H. W., Hurley, P. J., Natarajan, T. K., and Pitt, B. (197I). A noninvasive scintiphotographic method for detecting regional ventricular dysfunction in man. New England fournal of Medicine, 284, 1165.

Requests for reprints to Dr. Juhani Heikkilä, Cardiovascular Laboratory, University Central Hospital, \$290 Helsinki 29, Finland. 